العدد الثالث والأربعون

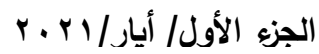

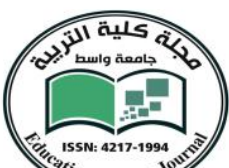

tion College 3

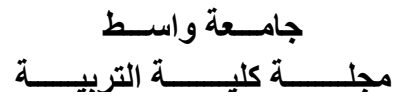

\title{
واقع سكك الحديد في العرلق وسبل تنميتها
}

م.د. منتهى طعيمة عناد

الجامعة المستصرية / كلية التربية الاساسية

\section{muntahairaq76@gmail.com}

المستخلص

يتتاول البحث دراسة واقع النقل بسكك الحديد في العراق، اذ يعاني هذا القطاع من تدهور ملحوظ في مستوى الخدمات المقدمة للمسافرين واصحاب البضائع، مما أدى الى عزوف معظم الاقراد عن اقتتاء هذه الواسطة للتنقل، على الرغم من أنه يعد من ارخص وسائط النقل. أن تهالك وقدم البنى التحتية لهذه الواسطة والمتمثلة بخطوط السكك والقاطرات والعربات جعلها تفتقر الى السرعة والراحة والامان، مما أدى الى خفض الطلب على خدمة النقل بالسكك الحديدية، على الرغم من اهمية هذه الواسطة في التقليل من الازدحامات المرورية التي أصبحت في تزايد مستمر نتيجة لازدياد اعداد السكان والمركبات.

أستند البحث على منهج التحليل الموضوعي للبيانات الرسمية وتحويلها الى جداول واشكال بيانية لسهولة المقارنة، اضافة الى المنهج الوصفي، للخروج بالنتائج النهائية التي توصل اليها البحث، وأيجاد بعض الحلول المناسبة للارتقاء بمنظومة النقل السككي في العراق.

الكلمات المفتاحية: تحليل واقع النقل الإككي،المشكلات التي تواجهه،مشاربع مقترحة لرفع الكفاءة 


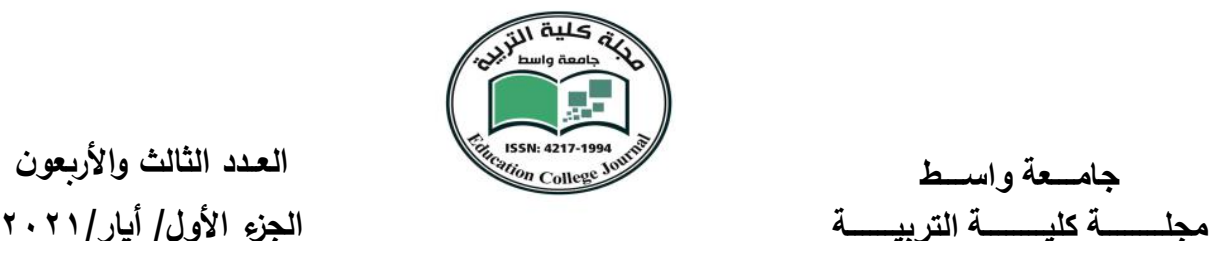

\title{
The reality of railways in Iraq and ways to develop them
}

\section{Dr.Muntaha Taima Enad}

Al Mustansiriy / College of Basic Education muntahairaq76@gmail.com

\begin{abstract}
The research deals with studying the reality of railway transportation in Iraq, as this sector suffers from a marked deterioration in the level of services provided to travelers and cargo owners, which has led to the reluctance of most individuals to acquire this means of transportation, despite it being one of the cheapest means of transport. The wear and tear of the infrastructure of this medium, represented by railways, locomotives and wagons, made it lack speed, comfort and safety, which led to a reduction in the demand for rail transport service, despite the importance of this method in reducing traffic congestion that has become continuously increasing as a result of the increase in population And vehicles, the research was based on the methodology of objective analysis of official data and converting them into tables and graphs for ease of comparison, in addition to the descriptive approach, to come out with the final results reached by the research, and to find some appropriate solutions to upgrade the rail transport system in Iraq.
\end{abstract}

Key words: analysis of the railway transport reality, problems it faces, proposed projects 


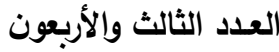

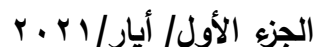
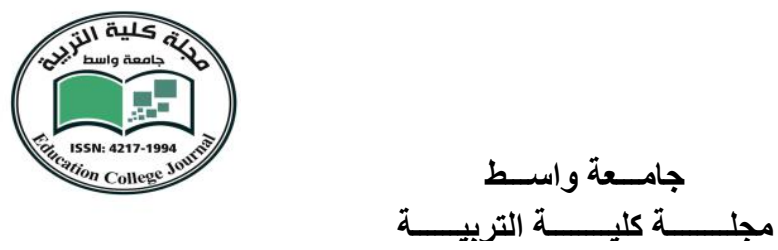

المقدمة

تعد السكك الحديدية من أهم وسائط النقل في العالم، لاسيما العراق فهي تشكل شرياناً حيوياً

واستراتيجيا فاعلاً في عملية التتمية، فقد أحدثت تغيرات كبيرة في العالم، وقلبت المفاهيم التي كانت

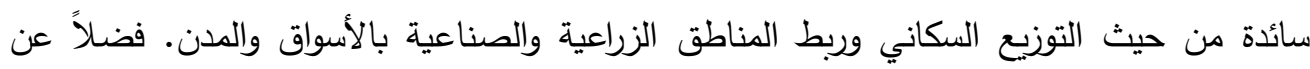
كونها وسيلة نقل امنة ونظيفة ومنخفضة التكلفة.

لذا بدأت العديد من دول العالم المتقدمة والنامية بعملية تطويرها واستثمارها بكفاءة أكبر.

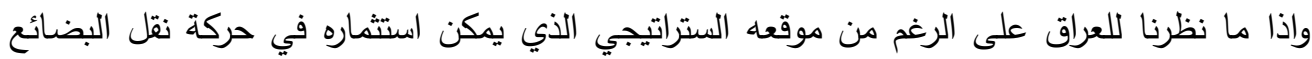
بتتشيط التجارة الخارجية من والى العراق بصفته محطة عبور الى دول العالم المختلفة عبر شبكة

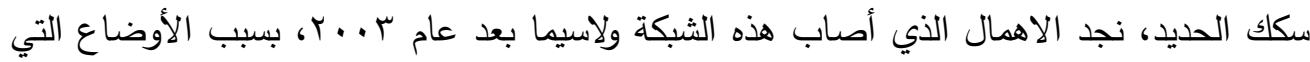

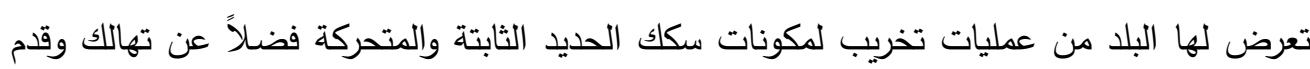
الثبكات والقاطرات وفقدانها لجزء كبير من مقومات السلامة والامان والسرعة والراحة. وعليه تمثلت مشكلة البحث بالتساؤل الآتي :

ا. هل ان ضعف البنى التحتية المتمثلة بخطوط سكك الحديد والوحدات المتحركة التي تشمل القاطرات والعربات أدى الى خفض الطلب على هذه الواسطة النقلية.

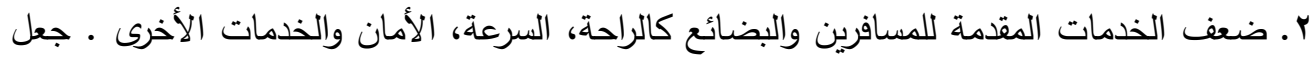

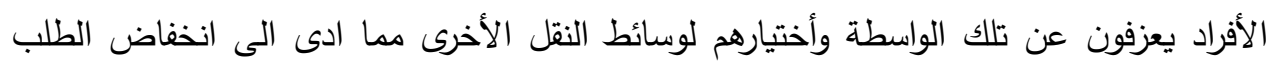
عليها. فرضية البحث أن عدم وجود خطة عمل واضحة وتخطيط صحيح في مجال النقل بسكك الحديد. كان أحد

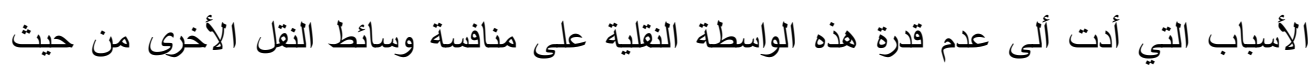

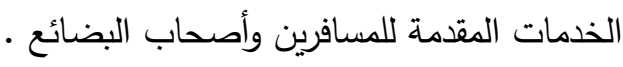
هاف البحث يهدف البحث الى تحليل واقع النقل بسكك الحديد في العراق والمشكلات التي تواجهه، و وضع المشاريع المقترحة التي تعمل على تطويره وتتميته. حدود البحث أعتمد البحث على بيانات السنوية لسكك الحديد ووزارتي التخطيط والنقل في العراق للددة .$(r+\mid V-r \cdot . r)$ 
العدد الثالث والأربعون

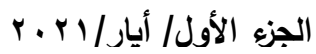

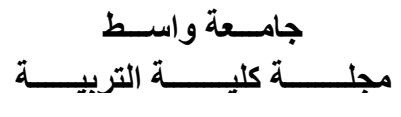

منهجية البحث

اعتمد البحث على المنهج الاستقرائي والاستتباطي، أضافة الى تحليل البيانات الخاصة بسكك الحديد، وتبويب البيانات في جداول وتحويلها الى اشكال بيانية لسهولة المقارنة وإبراز تباين نشاط سكك الحديد حسب نوع الخط. وعليه يتتاول البحث واقع سكك الحديد العراقية وفق التالي :

\section{تاربخ نشأة وتطور سكك الحديد في العراق}

شهد العراق أول خط حديدي لعربات الترام عام 1979 (م، عندما أقام الوالي العثماني مدحت باشا شركة ترامواي بغداد - الكاظمية وقد استخدمت الخيول لجر العربات وكان يعرف بالكاري . فيما بعد أنشأ خط مشابه ليربط النجف الأشرف بمدينة الكوفة. وقد كانت المنافسة شديدة بين المانيا وبريطانيا من أجل أنشاء خطوط سكك الحديدية في العراق، ففي عام r ·9 ام حصلت المانيا على امتياز من الحكومة العثمانية لأنثاء سكة حديد ((أقونية - اضنة - حلب - موصل - بغداد))

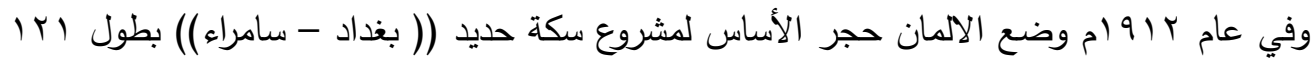
كم، وتم تسير أول قطار عليه ـأ ام بعدها تشكلت أدارة للسكك الحديد في العراق وكانت تحت سيطرة الجيش البريطاني ثم انتقلت الى أدارة مدنية بريطانية عام • ب أم ثم تحولت الى أدارة مدنية

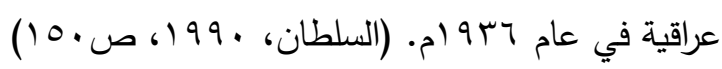
بعد انتهاء الحرب العالمية الأولى بوشر بتمديد خط سامراء - بيجي بعدها أمتد الى الثرقاط - الموصل وفي عام • ع ام تم تمديده الى الحدود السورية وربطه بالخطوط السورية والتركية ثم

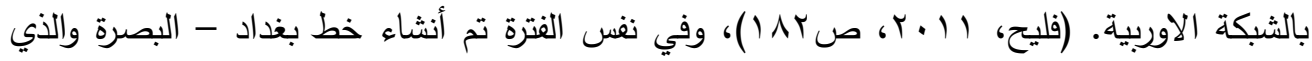
تبنته بريطانيا لخدمة اغراضها العسكرية، وخط حديدي رابط بين مدينتين بغداد - فلوجة وصولاً الى لى

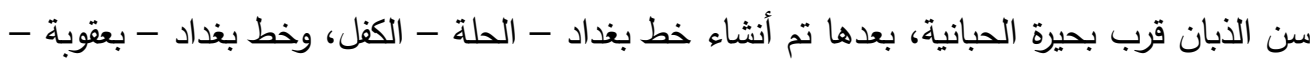

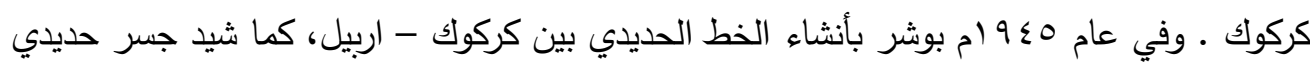
مشترك للقطارات والسيارات ببغداد (( جسر الصرافية ))، وبناء المحطة العالمية المركزية في عام

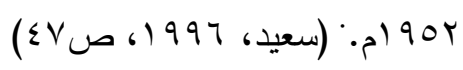
وتبنت الحكومة العراقية خلال خطط التمية القومية في فترة السبعينات والثمانينات من القرن الماضي تتفيذ مشروعات استراتيجية وبمواصفات من بينها الخط الحديدي بغداد - حصيبه عكاشات والذي يربط مناجم الفوسفات بالمعامل الرئيسة والأسمدة في عكاشات بموانئ البصرة ، 
العدد الثالث والأربعون

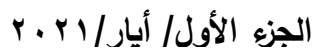

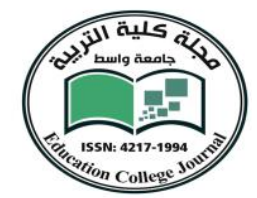

أضافة الى ربط العراق بسوريا عن طريق نهر الفرات، خط سكك حديد كركوك - بيجي - حديثة، وجزء من الخط القوسي مسيب - كربلاء - نجف - سماوة، وخط الموصل بزاخو وخط بغداد - القائم - حصيبه، وبسرعة تشغيلية لقطارات المسافرين ـ 1 ا كم/ساعة ولقطارات البضائع . 1 كم/ ساعة.

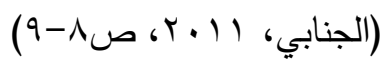
كما قدمت مشاريع عديدة منها ربط منطقتي صفوان والعمارة بخط سكة حديد بغداد - البصرة، فضلاً عن مشروع خطة سكة حديد العراق - الكويت، ومشروع خط سكة حديد العراق - الأردن.

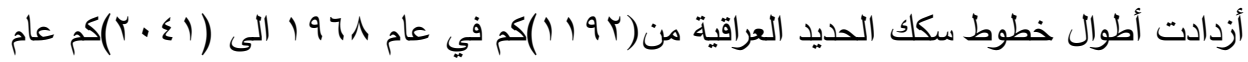

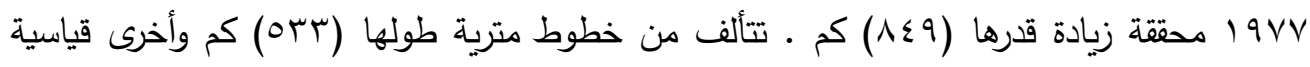
طولها ( 10.1 (10) كم. أدت هذه الخطوط دوراً في ربط مناطق العراق ببعضها البعض لاسيما أنها تمر بمناطق مهمة من الناحية الاقتصادية فضلاً عن أنها ربطت العراق مع سوريا وتركيا وسهلت عملية نقل البضائع

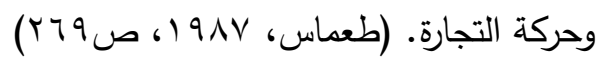

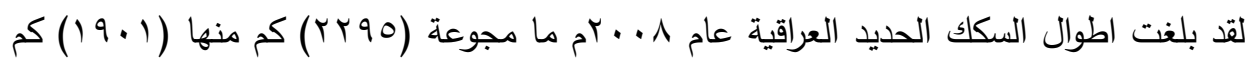

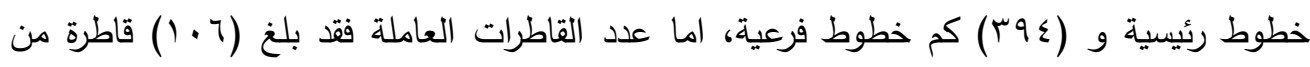

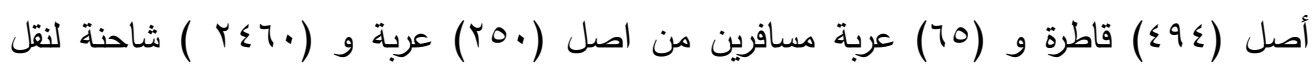

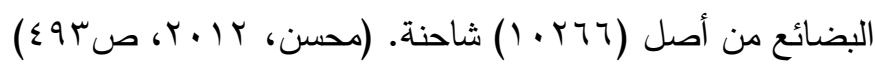

كانت الخدمات التي تقدمها سكك الحديد في مطلع الثمانينيات من القرن الماضي متطورة نوعاً ما نتيجة لاستبدال القاطرات القديمة بقاطرات فرنسية الا أنها تراجعت خلال سنوات الحصار الاقتصادي، اذ كان يتم تسيير ع قطارات يومياً. وقد بلغ عدد المسافرين من محطة قطار البصرة على سبيل المثال الى اكثر من 17 الف مسافر في

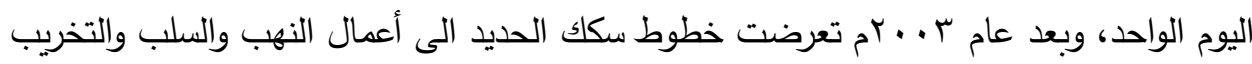
بالإضافة الى توقف خطوط المحافظات الغربية ـ تتظر خريطة رقم(1) 


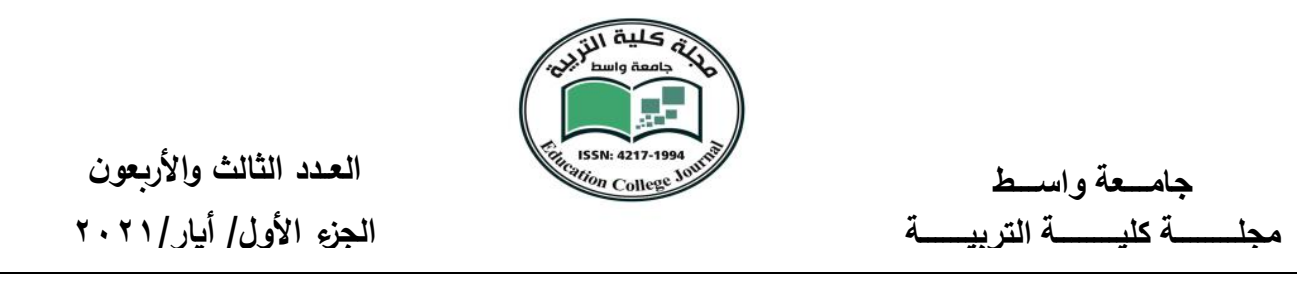

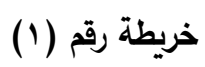

الخطوط الحالية لثبكة سكك الحديد العراقية

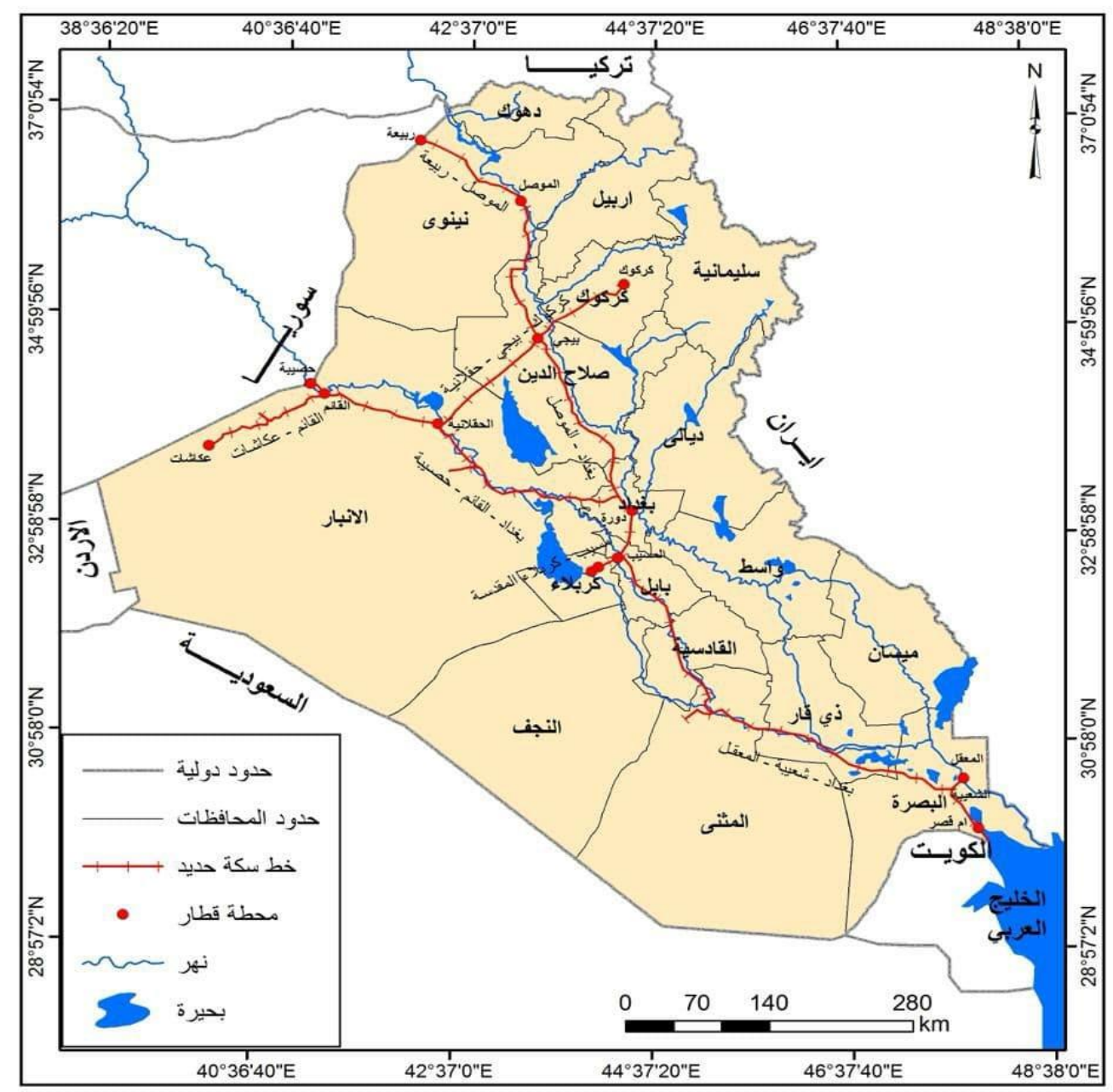

المصدر: من عمل الباحثة بالاعتماد على وزارة التخطيط، مديرية النقل والمواصلات، شعبة Gis.

7. أصبح خط بغداد - البصرة هو الخط الوحيد الذي يعمل في الوقت الحاضر وبسرعة لا تزيد على

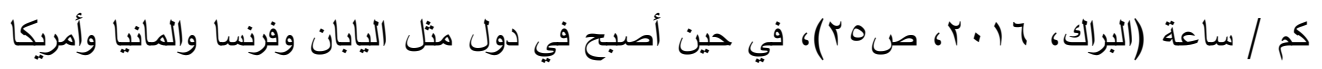
قطارات فائقة السرعة وهو أحد المعايير التي من خلالها تقاس كفاءة النقل. 
العدد الثالث والأربعون

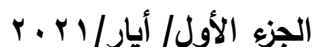

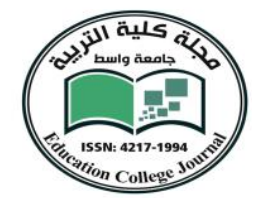

نشاط النقل بسكك الحديد في العراق

يعد النقل بالسكك الحديدية احد البنى الارتكازية للأقتصاد الوطني، من خلال مساهمته في الناتج المحلي لقطاع النقل. والذي يتمثل في الايرادات المتحصلة من نقل المسافرين والبضائع ـ لكن الذي نجده في سكك الحديد العراقية أنها تعاني من قلة الايرادات المالية المتحصلة من نشاطه الخدمي من نقل المسافرين والبضائع والذي زاد بعد عام ب. ..r نتيجة لعدم الاستقرار الامني والتخريب وتهالك الخطوط والقاطرات والعربات والتي جعلت من هذا القطاع يشكل عبئ على الاقتصاد الوطني بدلاً من أن يساهم في تتشيطه . وهذا ما سيتم ملاحظته من خلال الجدول (1) و (r) الذي يبين لنا اعداد المسافرين وحجم البضائع

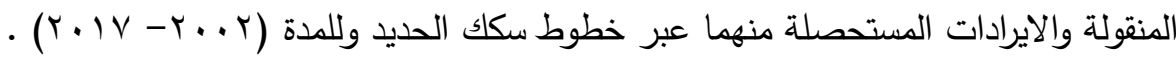
اعداد المسافرين المنقولين عبر خطوط السكك الحديلية يعد نقل المسافرين من الأنشطة المهمة التي يقوم بها النقل بسكك الحديد، يظهر من خلال

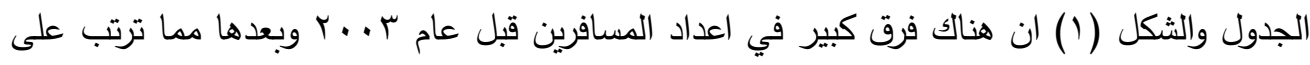
ذلك انخفاض مستوى الايرادات.

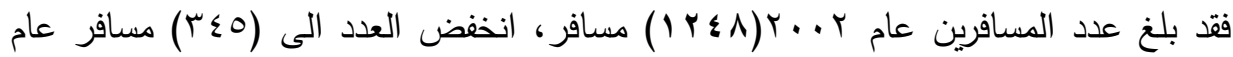
r . . r بفارق (r • 9) مسافر مما أنعكس ذلك على أنخفاض الايرادات .

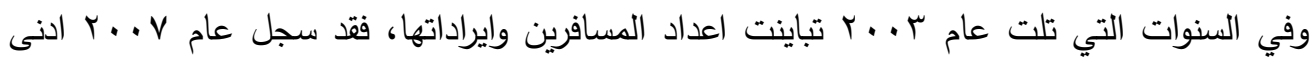

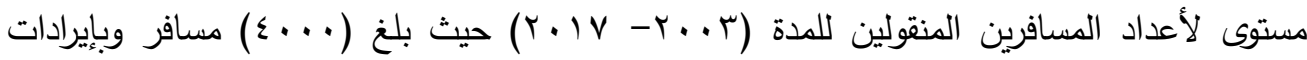
بلغت (10) مليون دينار ويعزى ذلك الى تراجع الوضع الامني وفقدان الحكومة العراقية السيطرة على معظم المحافظات وانتشار المجموعات المسلحة وارتفاع معدلات العبوات والتفجيرات، فضلاً عن صعوبة توفير الحماية للمسافرين، أستمر التراجع في أعداد المسافرين ومستوى الايرادات الى عام ^ . .. الذي سجل ارتفاع في عدد المسافرين ومستوى الايرادات والاعتماد الاكبر على خط بغداد - البصرة الذي يمر بعدد من المحافظات الجنوبية.

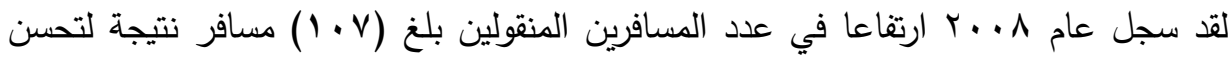

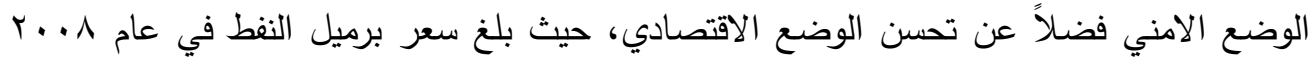

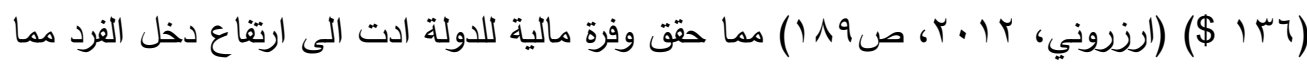
دفع المديرية العامة لسكك الحديد العراقية الى رفع تسعيرة السفر للدرجة الاولى ( ..... ب. دينار 
العدد الثالث والأربعون

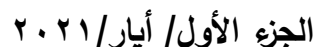

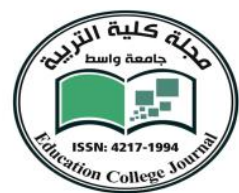

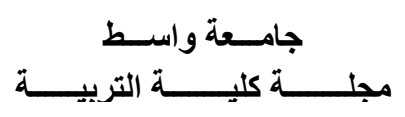

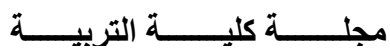

والدرجة الثانية ( . . . 1 (Y) دينار ، وسعر الدرجة الثالثة ( . . . V) دينار بعد ان كان سعر التذكرة لعام

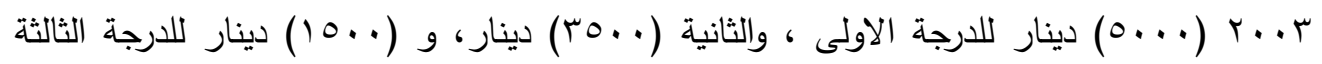

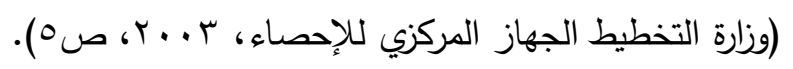

جدول (1) (1) (1) (1) (1)

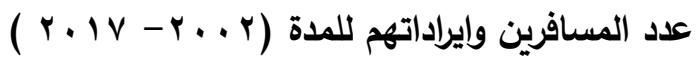

\begin{tabular}{|c|c|c|}
\hline $\begin{array}{c}\text { (مليون دينار) } \\
\text { (لايرادات }\end{array}$ & أعداد المسافرين & السنة \\
\hline $11 \%$. & $I r \leq 1$ & $r \ldots r$ \\
\hline PIq & $r \leq 0$ & $r \ldots r$ \\
\hline 07.0 & r & $r \ldots \varepsilon$ \\
\hline 0 & 7 & $r \ldots$ \\
\hline 17.7 & 11 & $r \ldots r$ \\
\hline 101 & $\varepsilon$ & $r \ldots v$ \\
\hline$V \varepsilon, . Y$ & $1 \cdot v$ & $r \ldots \wedge$ \\
\hline Y 100.1 & rY. & $r \ldots q$ \\
\hline rrqs & rir & $r .1$. \\
\hline $19 \leq 1$ & $I V A$ & $r .11$ \\
\hline 1019 & $1 \leq 1$ & $r .1 r$ \\
\hline $1 \leqslant \Lambda \Lambda$ & Ir & $r .1 r$ \\
\hline 1977 & $1 \leq 7$ & $r .1 \varepsilon$ \\
\hline$\varepsilon 70 Y$ & rqu & $r .10$ \\
\hline$\leq 1 \leq$. & $\{1 v$ & $r .17$ \\
\hline$\varepsilon r \mid r$ & $\varepsilon r 0$ & $r . I V$ \\
\hline
\end{tabular}

المصدر: وزارة التخطيط، الجهاز المركزي للإحصاء، مديرية احصاءات النقل والاتصالات،

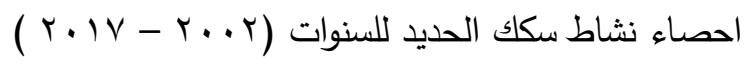


العدد الثالث والأربعون

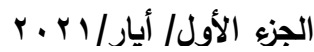

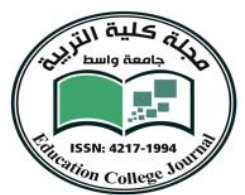

شكل (1)

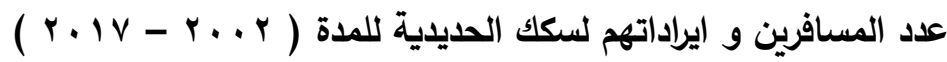

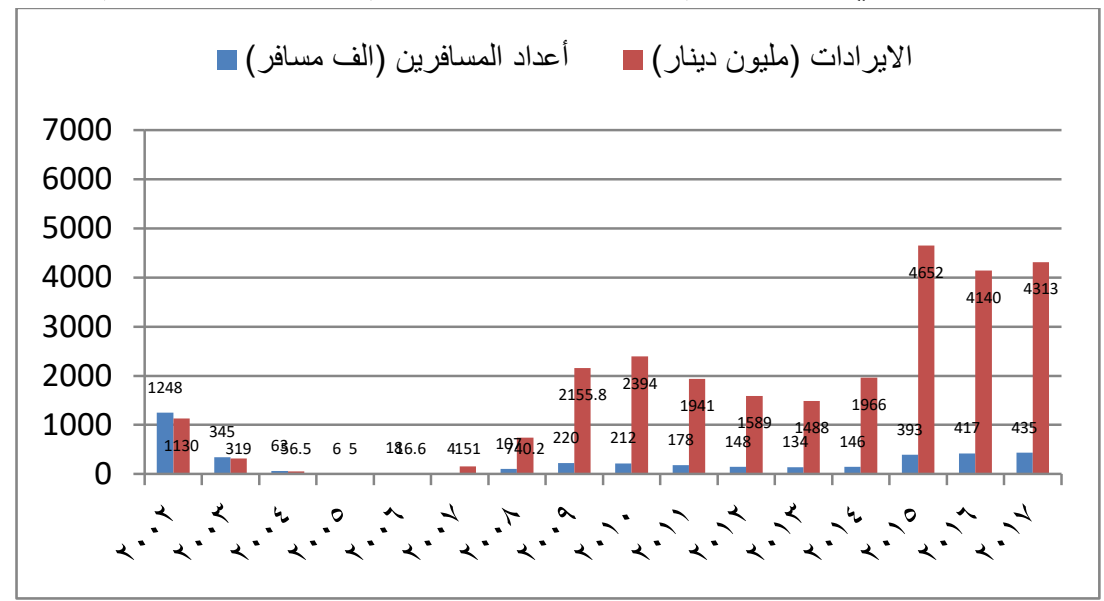

المصدر من عمل الباحثة بالاعتماد على جدول (1)

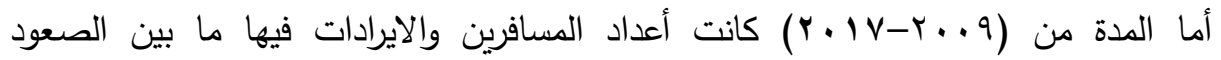
والنزول، وفق الوضع الامني والسرعة والراحة التي لاتلبي طموح المسافرين على الرغم من استيراد القاطرات الصينية، التي استخدمت على الخط بغداد - البصرة. بالإضافة الى تقارب اسعار اجور النقل بالسيارات واجور النقل على الدرجة الاولى والثانية. من خلال الجدول والثكل (Y) يتضح ان اغلب ايرادات نقل المسافرين خلال المدة (v . . r.

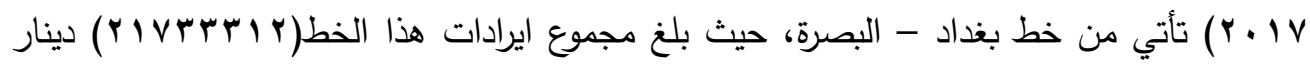

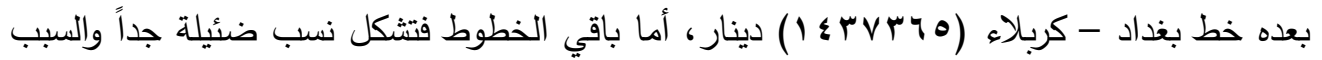
في ذلك ان اعداد المسافرين على خط بغداد - البصرة تكون ذات نسبة مرتفعة نتيجة كون هذا الخط يربط العديد من المحافظات الجنوبية، فهو يربط بين مدينة الحلة، المسيب، كربلاء، ديوانية، الناصرية، السماوة، فضلاً عن كونه يربط بين العاصمة بغداد ومحافظة البصرة التي تعد من أكثر لريط المدن الجنوبية تطوراً وذات جذب سياحي واقتصادي، مما أنعكس على حجم الايرادات، اما في باقي الخطوط فهناك نسبة قليلة من المسافرين بسبب الاوضاع الامنية غير المستقرة التي تمر عبرها تلك 
العدد الثالث والأربعون

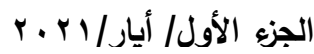

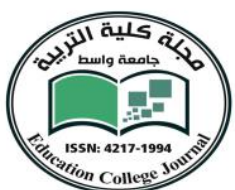

جدول (r)

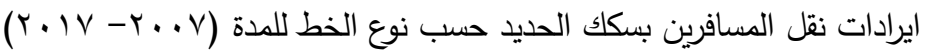

\begin{tabular}{|c|c|c|c|c|c|c|}
\hline موصل - تركيا & موصل-سوريا & بغداد-كربلاء & بغداد-الحقلانية & بغداد - سامراء & بغداد - بصرة & السنة \\
\hline- & - & - & - & - & $10 \leqslant .7$ & $r \ldots v$ \\
\hline- & - & - & - & - & $V E \cdot V_{10}$ & $r \ldots \Lambda$ \\
\hline- & - & - & $7 . Y \leq$ & $\leqslant 1 r \leqslant q$ & $r \cdot \varepsilon \cdot Y T^{\circ}$ & $r \ldots q$ \\
\hline 9118 & oro & - & $\varepsilon V I V$ & $11 \leq Y \wedge$ & rrqAr.. & r. 1. \\
\hline- & - & - & - & rVTr & $194 \wedge 019$ & $r .11$ \\
\hline- & - & - & - & - & $10 \wedge 9 \ldots r$ & $r+1 r$ \\
\hline- & - & - & - & - & $1 \leqslant \wedge \vee q Y 0$ & r. r \\
\hline- & - & $71 \leq 0$ & - & - & 199.110 & $r .1 \leq$ \\
\hline- & - & TrY. & - & - & INO. Tr. & Y. 10 \\
\hline- & - & $v 11 \ldots$ & - & - & $r \leq r q \ldots$ & 4.17 \\
\hline- & - & $v i \leq \ldots$ & - & - & $\leq r \mid r q \leq 0$ & $r .1 \mathrm{~V}$ \\
\hline 9118 & oro & $1 \leq$ YVY & $1 \cdot v \leq 1$ & $00 \leqslant 1 \leqslant$ & rIVTrMIr & المجموع \\
\hline
\end{tabular}

المصدر: من عمل الباحثة بالاعتماد على: وزارة التخطيط ، الجهاز المركزي للإحصاء ، مديرية احصاءات

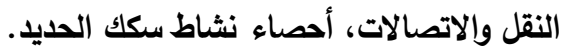

شكل (r)

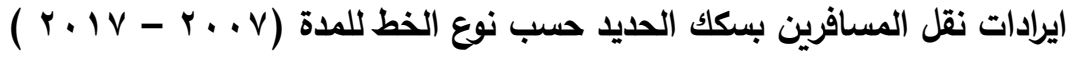

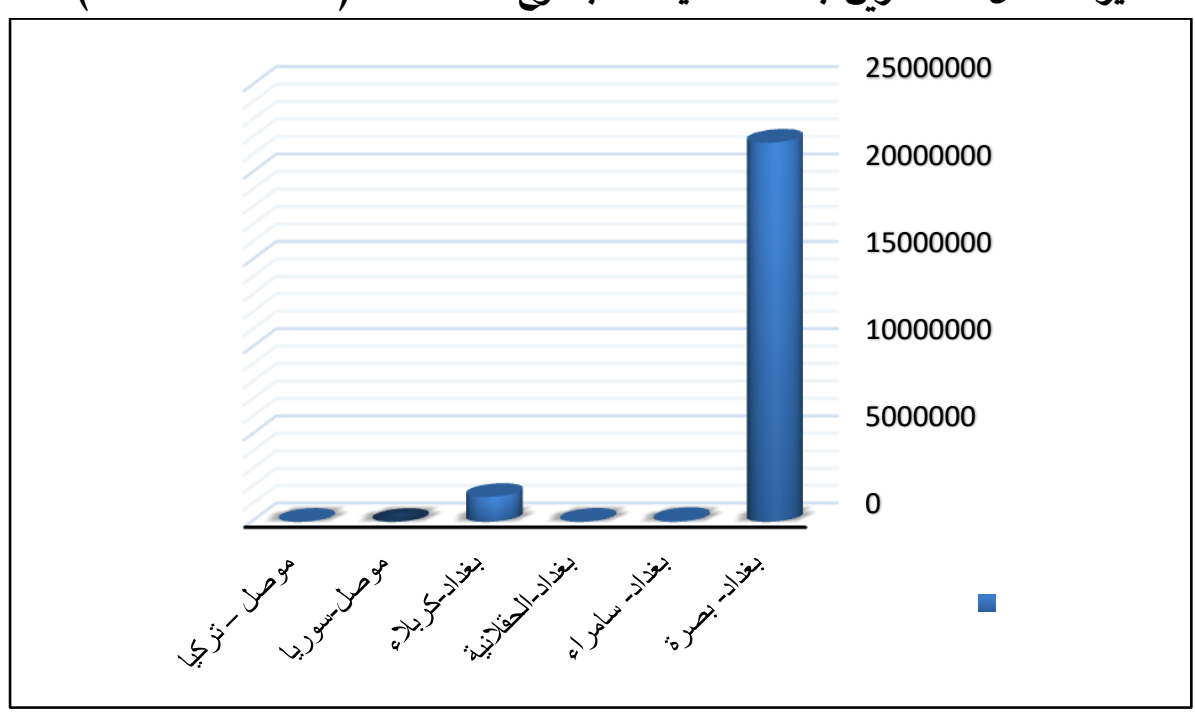

المصدر: من عمل الباحثة بالاعتماد على جدول (r) 
العدد الثالث والأربعون

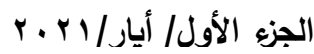

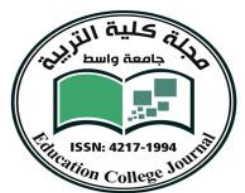

ition College 30

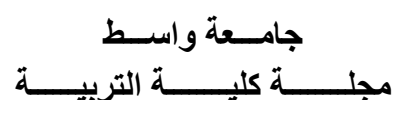

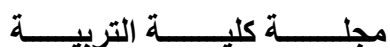

\section{كمية البضائع المنقولة عبر خطوط السكك الحديدية}

يعد نقل البضائع عن طريق السكك الحديدية مهمة من بين مهام هذا النوع من النقل، والاعتماد عليها يكون بشكل كبير لقدرتها الكبيرة على نقل الحمولات الثقيلة ولمسافات بعيدة كما ان اغلب ايرادات سكك الحديد تأتي من البضائع المنقولة عبر خطوطها ولاسيما على الخطوط التي تنقل الفوسفات ونقل النفط الخام والمواد الاخرى والبضائع القادمة من موانئ البصرة.

لقد انخفضت كمية البضائع المنقولة عبر سكك الحديد وبشكل واضتح بعد عام ب . . r نتيجة للأوضاع السياسية التي شهدها البلد فضلاً عن وجود أسباب أخرى أدت ألى تفضيل نقل البضائع عبر شاحنات النقل البري منها الاوضاع غير المستقرة وعدم التأمين على البضائع المنقولة عبر تلك الخطوط، وعدم توفر الامان والسرعة اللازمة مما أدى الى توقف اغلب الخطوط الناقلة للبضائع.

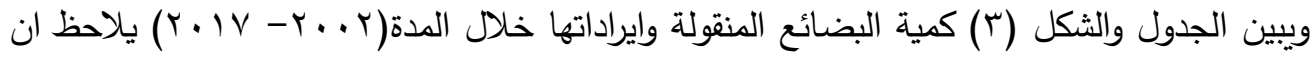

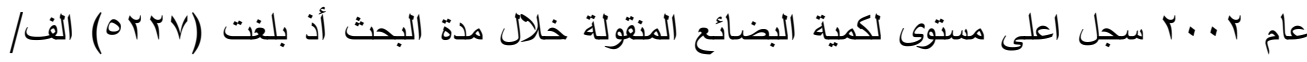
طن بإيرادات بلغت (Y Y RVV) مليون دينار • ويعود هذا الارتفاع الى استخدام سكك الحديد في نقل منتجات معمل الحديد والصلب في منطقة خور الزبير والاسمدة في منطقة ابو الخصيب والاسمنت من معمل سمنت ام قصر يضاف الى ذلك نقل الحبوب والنفط الخام بدأ الانخفاض في كمية البضائع

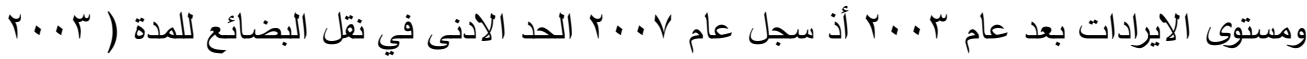

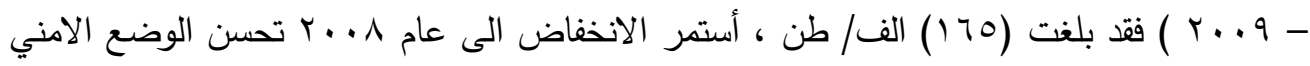

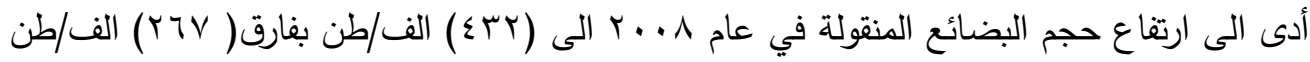

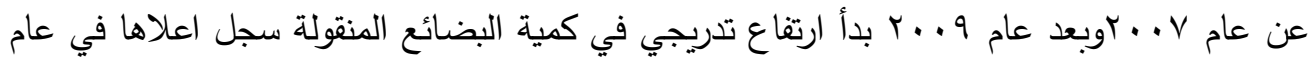

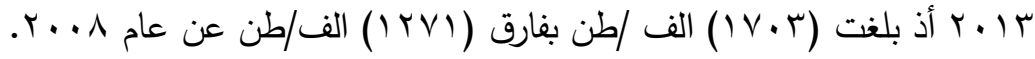


العداد الثالث والأربعون

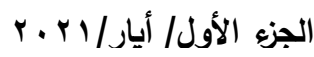

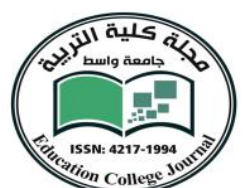

irion College

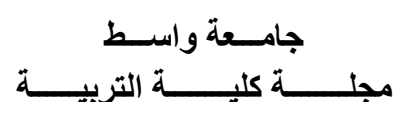

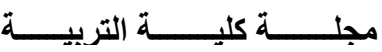

جدول (r)

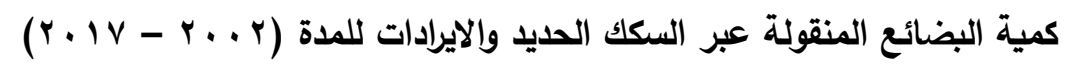

\begin{tabular}{|c|c|c|}
\hline الايرادات (مليون دينار) & كميات البضائع الف / طن & السنة \\
\hline rYษAV & OrYV & $r \ldots r$ \\
\hline $0 \leqslant \wedge \neg .7$ & 1479 & $r \ldots r$ \\
\hline$\varepsilon q \vee \vee$ & $\varepsilon r q$ & $r \ldots \varepsilon$ \\
\hline Irrq & rre & r...o \\
\hline 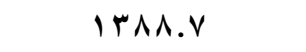 & roq & $r \ldots T$ \\
\hline $1 . \leqslant 9$ & 170 & $r . . v$ \\
\hline$\varepsilon r \mid \wedge$ & $\varepsilon r r$ & $r \cdot \Lambda$ \\
\hline 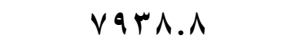 & $7 \leq \varepsilon$ & $r \ldots q$ \\
\hline 117.7 .0 & 990 & $r \cdot 1$. \\
\hline $1 \ldots 1 \varepsilon$ & 79. & $Y .11$ \\
\hline $1 . .97$ & ^०. & $r+1 r$ \\
\hline 11080 & $1 v \cdot r$ & $r \cdot 1 r$ \\
\hline V.rY & $1.7 \mathrm{~V}$ & $Y \cdot 1 \varepsilon$ \\
\hline ( & ITs & $Y .10$ \\
\hline 119 & 07 & $Y .17$ \\
\hline 107. & $1 \cdot \varepsilon$ & $r+1 V$ \\
\hline
\end{tabular}

المصدر: وزارة التخطيط، الجهاز المركزي للإحصاء، مديرية احصاء النقل والاتصالات، مصدر سابق. 
العدد الثالث والأربعون

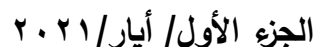

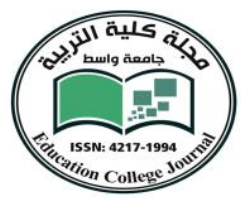

شكل (r)

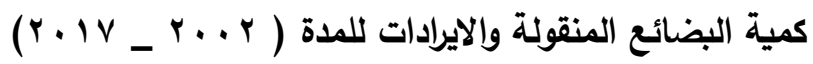

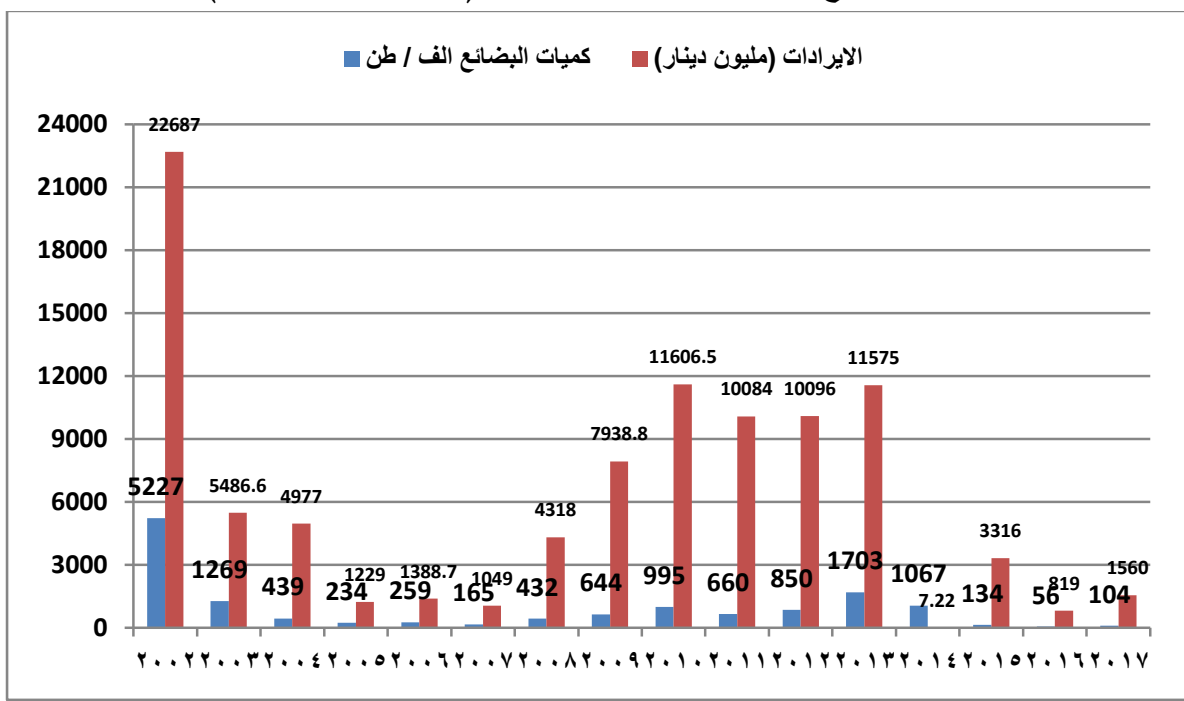

المصدر: من عمل الباحثة بالاعتماد على جدول (r)

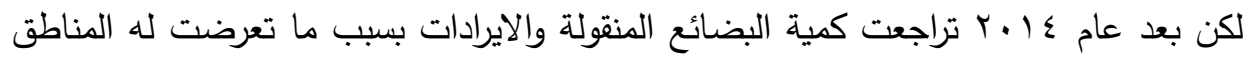

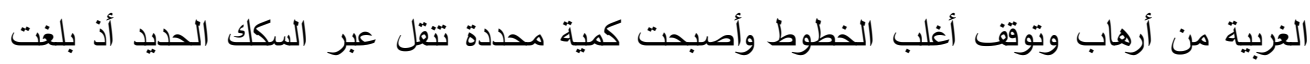

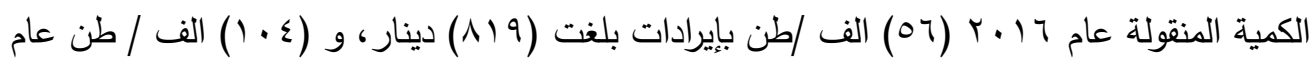

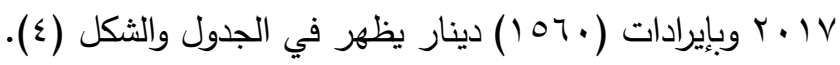

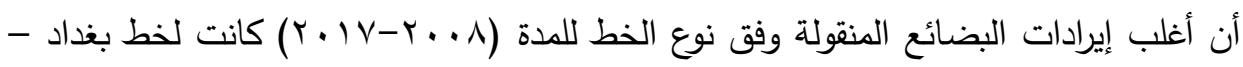

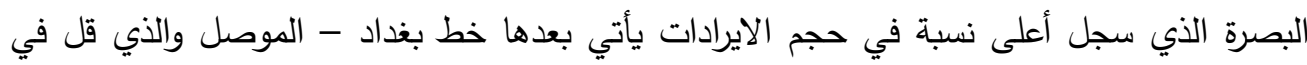

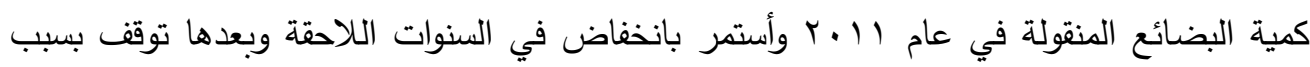

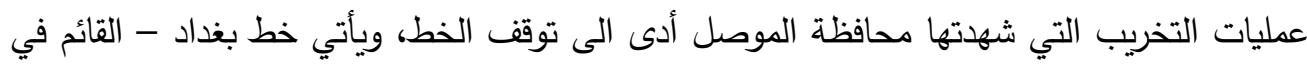

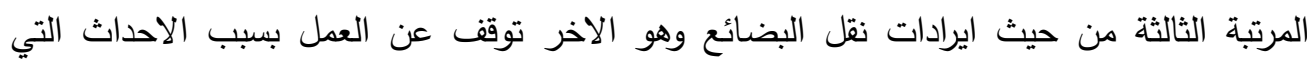

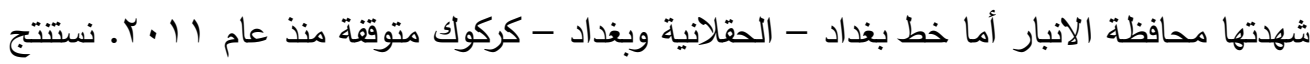

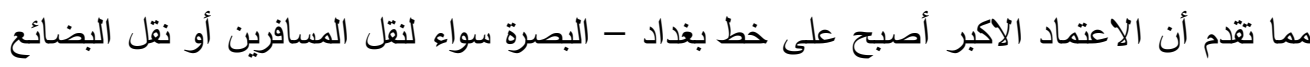

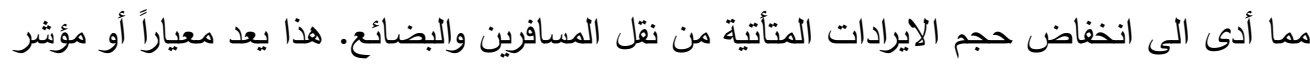

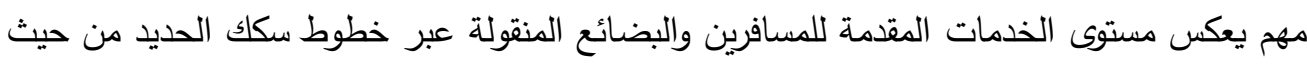

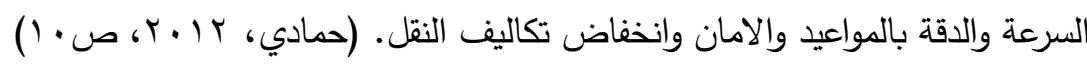


العدد الثالث والأربعون

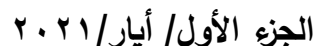

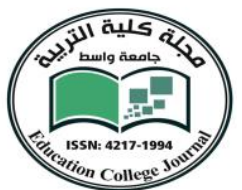

جدول (๕)

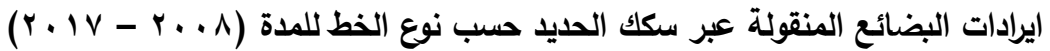

\begin{tabular}{|c|c|c|c|c|c|}
\hline بغداد - بيجي - كركوك & بغداد-بيجي- حقلانية & بغداد - القائم & بغداد - الموصل & بغداد - البصرة & السنة \\
\hline- & - & rergy & דוצזי.. & $r \cdot \Lambda \cdot v \wedge v$ & r... \\
\hline ए৭११०^ & - & $91 . \wedge r r$ & 1791797 & \&9Mтrอ. & r...q \\
\hline- & $V .70$. & 17117 & $r . \leq 0 \leq q$. & 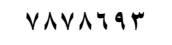 & r.l. \\
\hline- & - & rYAqAO & qrrari & צヘצIYYY & $r .11$ \\
\hline - & - & $r O V \leqslant O r$ & $q r r \leqslant \leqslant V$ & $00 \wedge \wedge \leqslant r Y$ & $r \cdot I r$ \\
\hline- & - & r.q१४१ & 7.797. & 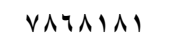 & $r .1 r$ \\
\hline- & - & $9 \cdot r \ldots 7$ & $79 \ldots$ & IIIV7V & r.lı \\
\hline- & - & - & - & - & $r+10$ \\
\hline- & - & - & - & ヘ1ヘтा9 & $r .14$ \\
\hline - & - & - & - & VR.TYr & $r+1 v$ \\
\hline r१११९८ & $V .70$. & r..0.14 & VYrI. A. & \&MAT $\leqslant \vee \backslash V$ & المجموع \\
\hline
\end{tabular}

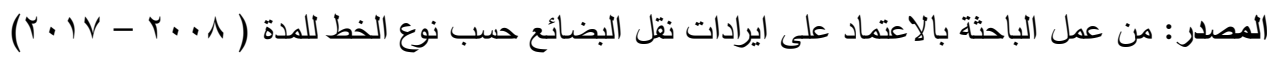

شكل (ع)

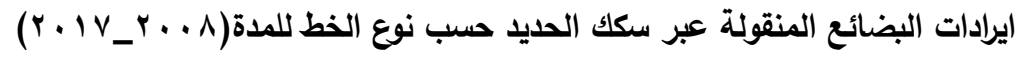

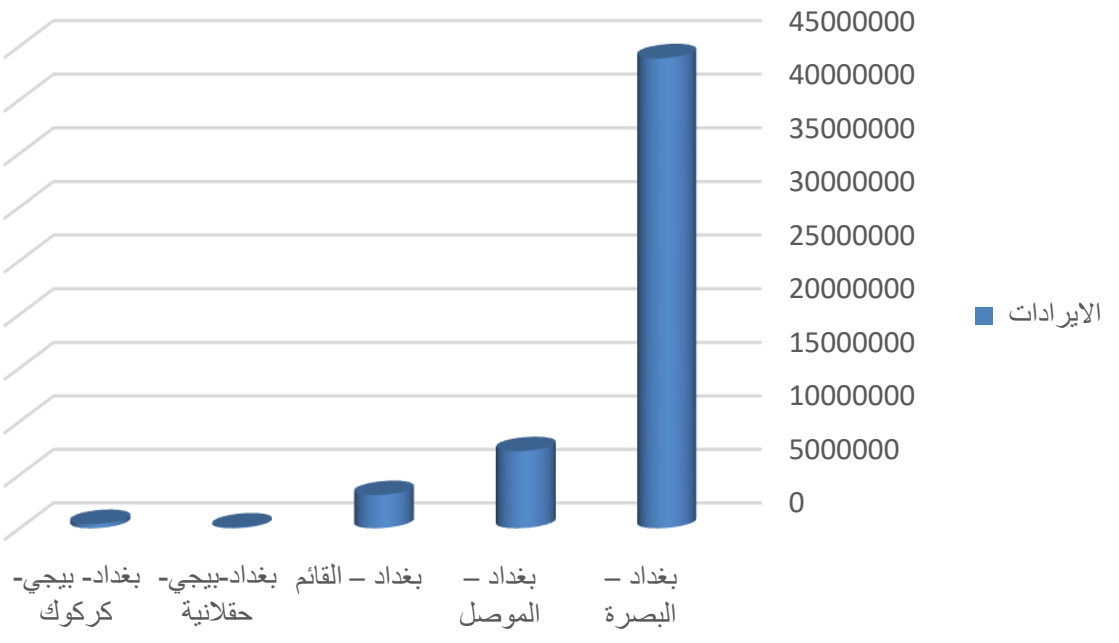

المصدر : من عمل الباحثة بالاعتماد على جلول (؛) 
العدد الثالث والأربعون

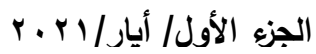

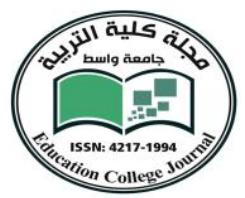

وعليه فأن خطوط سكك الحديد العراقية تعاني من تدني مستوى الخدمات المقدمة للمسافرين

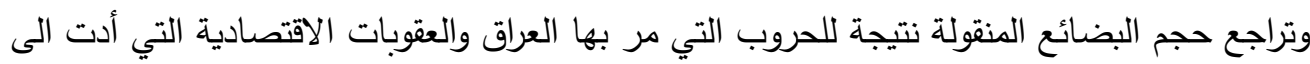

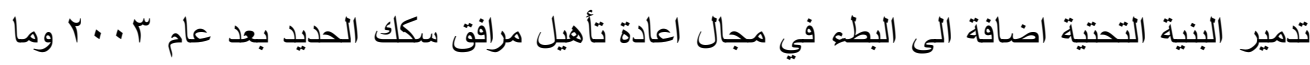
رافقتها من مشكلات مالية عدت من اهم المعوقات التي تواجه تطور هذا القطاع والتي يمكن تتاولها كما يلي : رلان

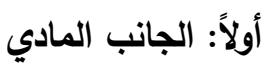

أصبحت الثركة العامة لسكك حديد العراق تعاني من عجز مالي نتيجة لتدني المردودات المالية

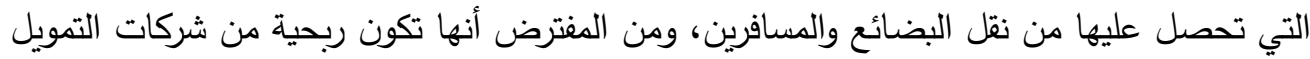

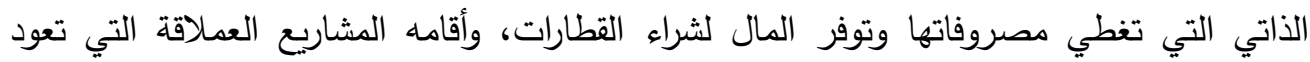

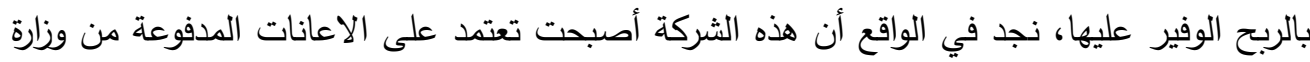

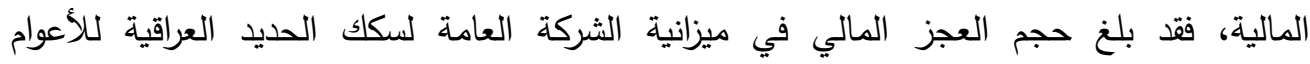

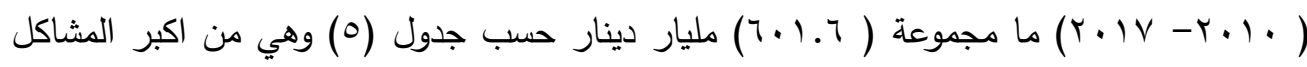
والتحديت التي تواجه قطاع النقل بسكك الحديد .

ثانياً : القوى العاملة

لاستكمال المؤشرات التي تبين واقع النقل بسكك الحديد سوف نلقي الضوء على حجم القوى

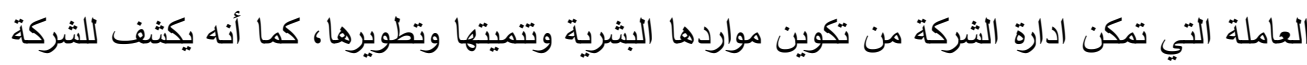

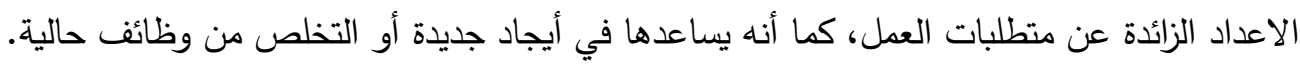

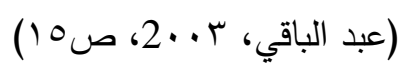

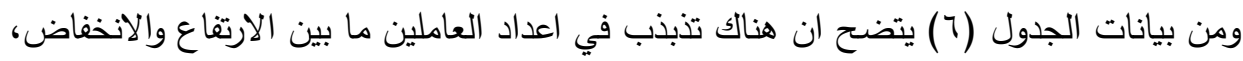

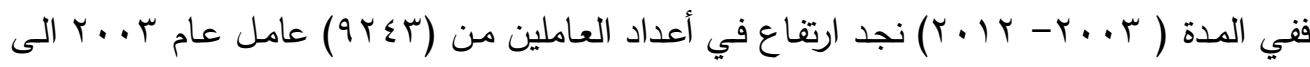

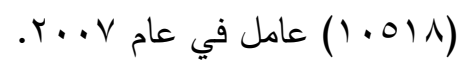

ويعزى هذا الارتفاع الى أعادة تعيين المفصولين السياسيين فضلاً عن تعيين اعداد اخرى بأوامر

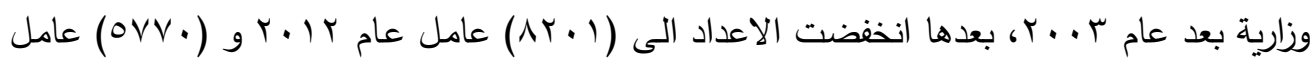

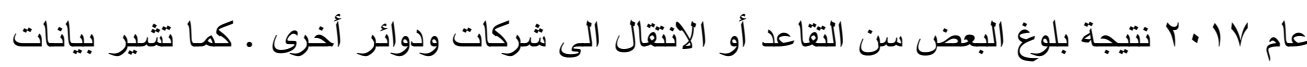

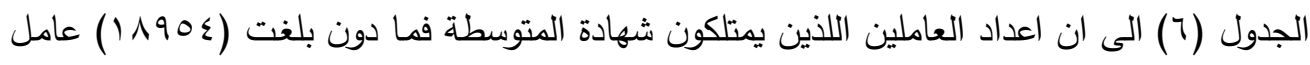

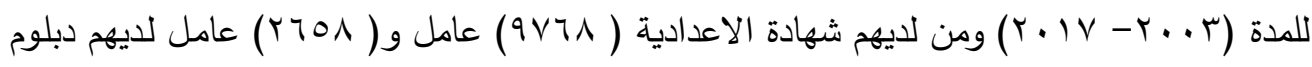

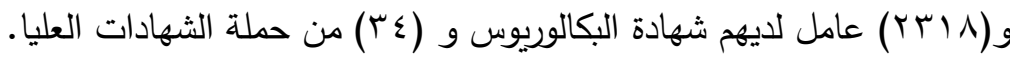


العدد الثالث والأربعون

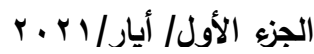

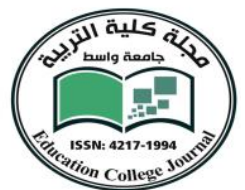

ation College 3

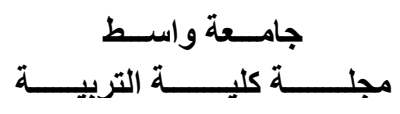

وعليه يلاحظ ارتفاع اعداد العاملين اللذين يمتلكون شهادة الابتدائية فما دون مما يعني هذا

افتقـار النقل بسكك الحديـد الـى الاختصاصـات والكفـاءات، ممـا يتطلب ذلك عمل دورات تدريبيـة

وتأهيلية للنهوض بأداء الثركة العامة لسكك الحديد العراقية.

جدول (0)

حجم العجز المالي في ميزانية الثركة العامة لسكك الديد العراقية

\begin{tabular}{|c|c|c|c|}
\hline حجم العجز بالمليار & المصروفات بالمليار & الايرادات بالمليار & السنة \\
\hline $94 . \%$ & Ar. ${ }^{\prime}$ & 17.8 & $r \cdot 1$. \\
\hline $9 \leq .0$ & 90 & .0 & $r .11$ \\
\hline Ar & 94.0 & 11 & $r \cdot 1 r$ \\
\hline$\Lambda \cdot . r$ & AV.r & $v$ & $r \cdot 1 r$ \\
\hline $70 . r$ & Ar.r & iv & $r+1 \leq$ \\
\hline VI.s & $\Lambda . . \varepsilon$ & 9 & $r+10$ \\
\hline vi.0 & V9.0 & $\wedge$ & $r .17$ \\
\hline$v \cdot .7$ & จ^. & $\wedge$ & $r .1 V$ \\
\hline 7.1 .7 & 979 & V५. & المجموع \\
\hline
\end{tabular}

المصدر : من عمل الباحثة بالاعتماد على : وزارة النقل والمواصلات،الشركة العامة لسكك الحديد العراقية،

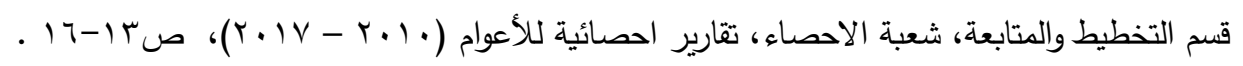

جدول (7)

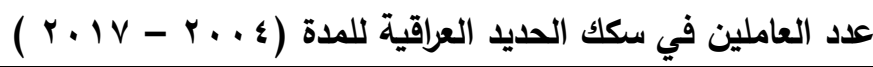

\begin{tabular}{|c|c|c|c|c|c|c|c|}
\hline النسبة & المجموع & فما دون & الاعدادية & الدبلوم & البكالوريوس & الثهادات العليا & السنة \\
\hline$r V . \varepsilon$ & $q r \leq r$ & $\Delta 9 \wedge$. & rro. & $r$ r. & rsi & ir & $r \ldots r$ \\
\hline ri.r & 1.011 & 917. & rADO & VYo & VYY & ir & $r \ldots v$ \\
\hline$r \leq . r$ & Ar.l & sorq & rrqu & $1 \leqslant 1$ & 710 & 7 & $r .1 r$ \\
\hline 18.1 & ovv. & rYVo & rrv. & Tro & 097 & $\varepsilon$ & $r .1 r$ \\
\hline$\% 1 \ldots$ & rrVTr & $1 \wedge 90 \leq$ & $9 \vee \neg \wedge$ & r.OA & ris & $r \varepsilon$ & المجموع \\
\hline
\end{tabular}

المصدر: من عمل الباحثة بالاعتماد على وزارة النقل والمواصلات، الثركة العامة لسكك الحديد العراقية، قسم التخطيط

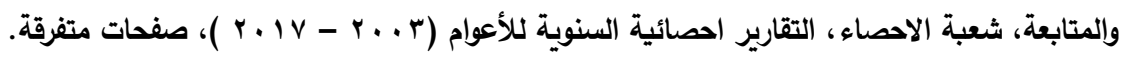


العدد الثالث والأربعون

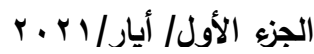

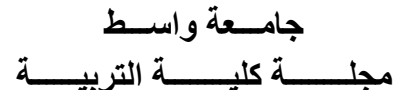

ثالثاً : تلكؤ المشاريع

وضعت مديرية السكك الحديدية العديد من المشاريع من أجل النهوض بواقع سكك الحديد العراقية ورفع كفاءة منظومة النقل. وجدول (V) يوضح المشروعات المخططة والتي وصلت المدة المقررة لإنجاز البعض منها الى 10 سنة ولم تتجز لغاية الان . فعلى سبيل المثال مشروع خط سكة ( السماوة - ناصرية - غبيشة ) المتعاقد عليه في عام ع ... كانت المدة المقرة لإنجاز سا سنة وقد وصلت نسبة الانجاز الفعلي لهذا المشروع عام

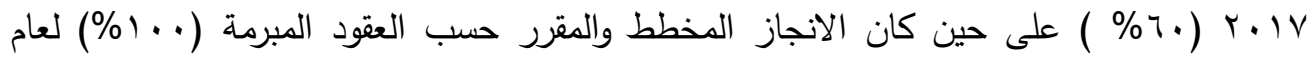

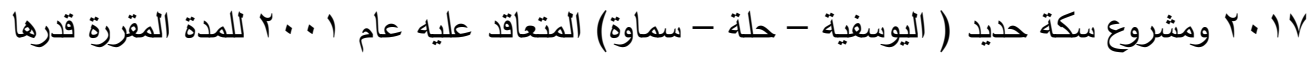
10 سنة وصلت نسبة الانجاز الفعلي لعام Y V. V (070\%) ومشروع خط السكة الدائري حول مدينة

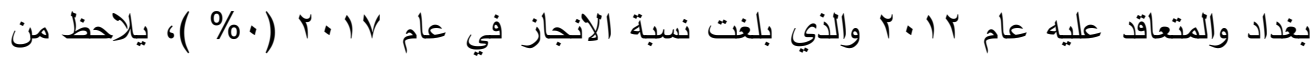
الجدول (V) أنه هناك اختلاف كبير بين الانجاز المخطط والفعلي للمشروعات، مما يدل ذلك على عدم أحالة هذه المشاريع الى شركات رصينة تملك من الخبرات ما يؤهلها لإنجاز هذه المشاريع ضمن

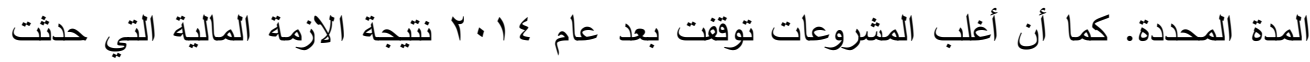
جراء أنخفاض أسعار النفط والتي أدت الى توقف العمل بتنفيذ تلك المشروعات وفق الخطط المعمولة

جدول (V) بعض المشروعات المتلكئة للسكك الحديدية

\begin{tabular}{|c|c|c|c|c|}
\hline 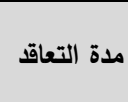 & ن الانجاز الفعلي & ن الانجاز المخططة & 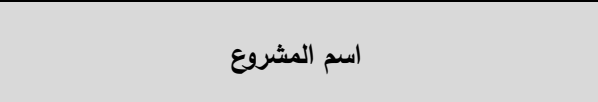 & $ت$ \\
\hline 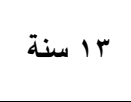 & $\%$ ४ & $\% 1 \ldots$ & سكة حديد ( سماوة - ناصرية -غبيثة ) المباشرة & -1 \\
\hline l 10 سنة & $\%$ ro & $\% 1 \ldots$ & سكة حليد ( يوسفية - حلة - سماوة) المباشرة ب ... r & $-r$ \\
\hline 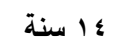 & $\% \vee$. & $\% 1 \ldots$ & سكة حليد ( غبيشة - بصرة - ام قصر) المباشرة r... r & $-r$ \\
\hline 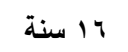 & $\%$. & - & 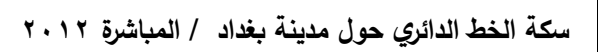 & $-\varepsilon$ \\
\hline 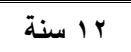 & $\%$. & $\%$ \% & سكة حليد ( رمادي - كربلاء) المباشرة r. r. P & -0 \\
\hline 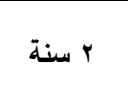 & $\%$. & $\%$. & تصاميم لمنظومة الاشارات والاتصالات للخطوط الحالية & -7 \\
\hline
\end{tabular}

المصدر : من عمل الباحثة بالاعتماد على وزارة النقل والمواصلات، الشركة العامة لسكك الحديد العراقية، تقرير

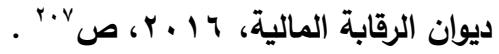


العداد الثالث والأربعون

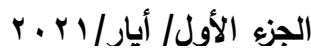

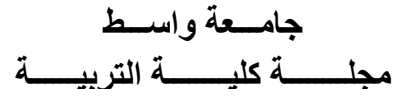

رابعاً : مشاكل أخرى

توجد مشاكل عدة في قطاع النقل بسكك الحديد منها : • تقادم خطوط السكك الحديدية : تعاني اجزاء كبيرة من الخطوط من قدم تصميمها، ولم تلبي

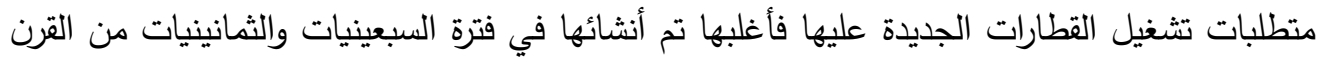

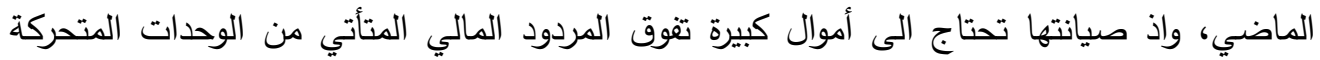
(القطارات) وخاصة قطارات المسافرين ـ فضلاً عن عدم قدرتها على تقديم خدمة مرضية للمسافرين

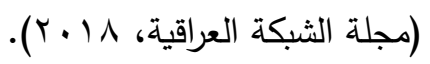
• انخفاض كفاءة تشغيل منظومة الاشارات والاتصالات لخطوط الثبكة بسبب قدمها وعطل الكثير

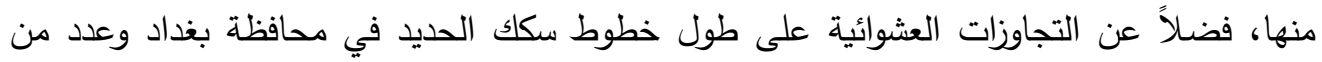

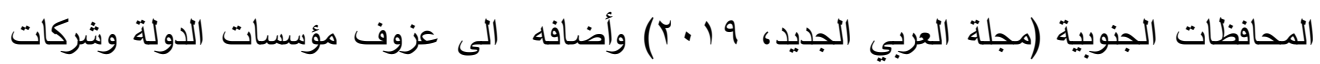

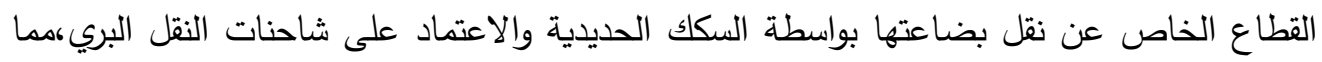
يسبب خسارة مالية كبيرة للشركة العامة لسكك الحديد العراقية.

\section{بعض السيناريوهات المقترحة لرفع كفاءة النقل لسكك العديد في العرلق :} يظهر من خلال تحليل البيانات الاحصائية التي تم ذكرها سلفاً ان الشركة العامة لسكك الحديد

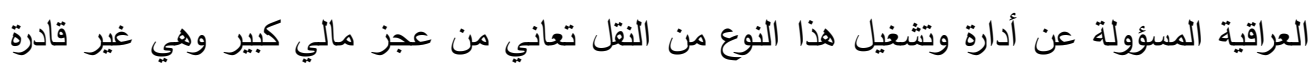
في الوقت الحاضر على هيكلة هذا القطاع الذي لابد من تطويره بما يتقق مع التغييرات التي تطرأ

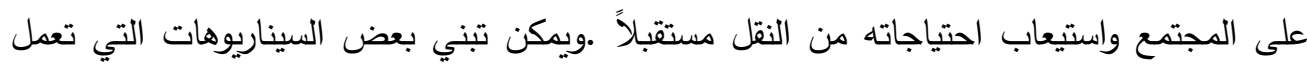
على رفع كفاءة النقل بسكك الحديد ووفق الامكانيات المتاحة وهي كالاتي :-

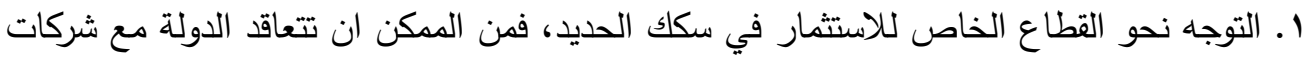
متخصصة في مجال السكك الحديدية لنظوير الثبكة وتوسيعها وتحديث منظومة الاتصالات

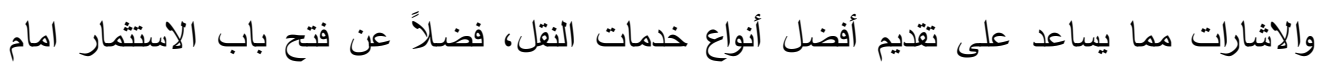
الثركات العالمية المتخصصة وتوفير البيئة المناسبة لها وتقديم كافة التسهيلات للعمل في العراق،

$$
\text { ويعد هذا الاسلوب من أنجح الأساليب في العديد من دول العالم . }
$$

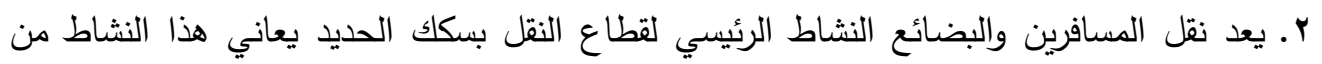

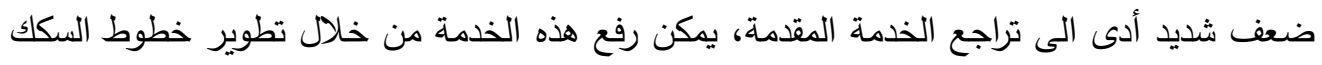
الحديدية الحالية لاسيما خطوط المناطق الغربية، اغلب الخطوط بحاجة الى اعادة بناء لغاء لأنها تمثل

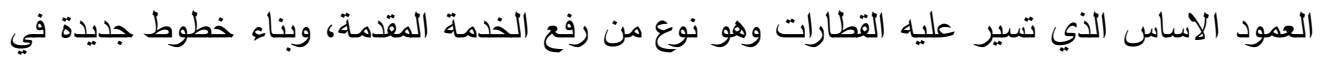


العدد الثالث والأربعون

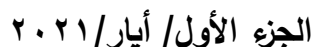

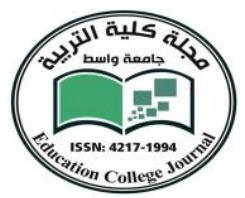

مناطق الجذب السياحي والديني لخط رابط بين النجف - كربلاء - كاظمية - سامراء، واحياء مشروع مترو بغداد الذي تعاقدت عليه امانه بغداد مع شركة سيسترا الفرنسية منذ عام ^ ... والذي يعمل على ربط مناطق بغداد كافة والتقليل من الازدحام المروري ويشكل مورداً أساسياً للدولة. بالإضافة الى بـ ئى تحديث القطارات والثاحنات والعربات وتوفير محطات حديثة ومتطورة تساعد على زيادة اعداد المسافرين وكمية البضائع المنقولة كما تعد السرعة والامان والراحة وتوفير مواعيد تتاسب المسافرين وبأسعار مخفضة من اهم العوامل التي تساعد في رفع الطلب على السكك الحديدية وتجعله منافساً لبقية وسائل النقل الاخرى. r. تشجيع مؤسسات ووزارات الدولة للتوجه لسكك الحديد في نقل بضاعتها وبالخصوص وزارة النفط والتجارة مما يساعد على نقل كميات كبيرة من المشتقات النفطية ومواد البطاقة التموينية من والى جميع محافظات العراق،ولن يتحقق ذلك الا بتطوير هذا القطاع •

\section{الاستنتاجات والتوصيات$$
\text { اولاً :- الاستتتاجات }
$$

ا ـ تعاني السكك الحديدية في العراق من تقادم وتهالك معظم خطوط السكة مما أدى الى تلكؤ سير القطارات ـ اضـافة الى الظروف والاحداث السياسية والاقتصـادية التي مر بها البلد والتي أدت الى توقف معظم الخطوط بين المحافظات وخاصـة المحافظـات الغربية التي جرى بها عمليات تخريب الخطوط وتوقفها عن الخدمة وعطل أنظمة الاشارات والاتصالات مما كان لله أثر سلبي على حركة

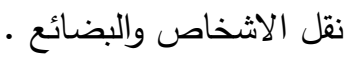
r ـ تدني مستوى الخدمة المقدمة للمسافر والبضائع المنقولة أدى ألى انخفاض الطلب على هذا النوع من النقل وتحول الافراد واصحاب البضائع الى وسيلة نقل بري اخرى. r. انخفاض الايرادات المتأتية من نقل المسافرين والبضـائع نتيجة لانخفاض اعداد المسافرين وكمية البضائع المنقولة بسبب تردي الخدمات وعزوف الافراد على النقل بهذه الواسطة . ـ. أصبح النقل بسكك الحديد يعتمد على خط بغداد - البصرة في نقل المسافرين والبضائع. والذي يعد أهم خط حديدي في العراق لربطه الموانئ العراقية ببقية محافظات العراق وتوقف بقية الخطوط بعائ عن العمل منذ عام \& ا ـ r مما أثر على حركة نقل البضـائع والافراد، فضـلاً عن أن الخطوط العاملة حالياً لا تتماشى مع السرعة الهائلة التي وصلت لها القطارات في باقي دول العالم. فعلى سبيل المثال 


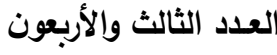

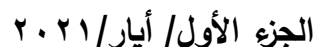

رحلة بغداد - البصرة تستغرق ((1) (1) ساعة للوصول الى البصرة بينما في مركبات القطاع الخاص يكون الوقت أقل من 1 ساعات مما ساعد على عزوف الافراد عن استعمال النقل بالسكك. ه. التلكؤ في تتفيذ المشاريع وفق المدة التعاقدية بسبب غياب التخطيط، وعدم وجود خطـة عمل التصل واضحة، بسبب تفثي الفساد المالي والاداري في قطاع سكك الحديد العراقية .

\section{ثانياً : التوصيات}

ا. العمل على تطوير النقل بسكك الحديد في العراق، من خلال أدخال التتنيات الحديثة ورفع مستوى

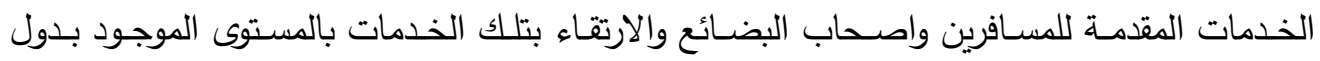

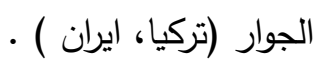

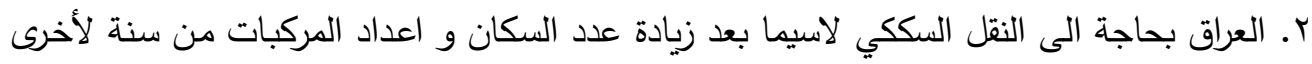

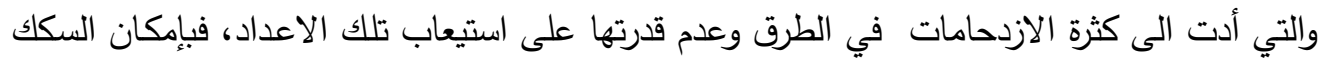

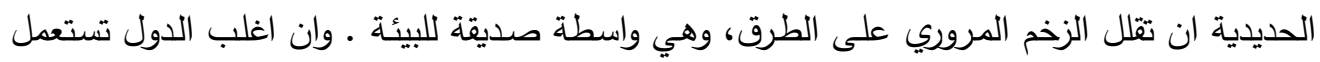

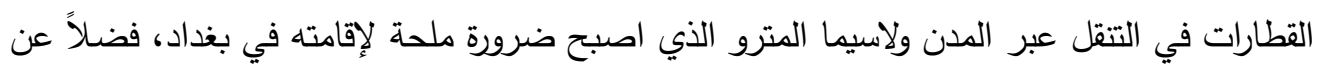

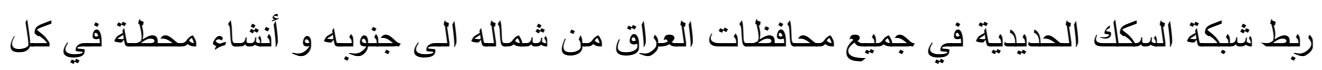
محافظة لتكون منظومة نقل متكاملة . r. العمل على تطوير اداء الثركة العامة لسكك الحديد العراقية كونها المسؤولة عن ادارة قطاع النقل

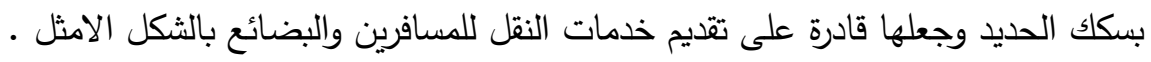

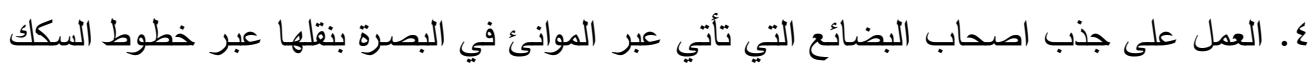

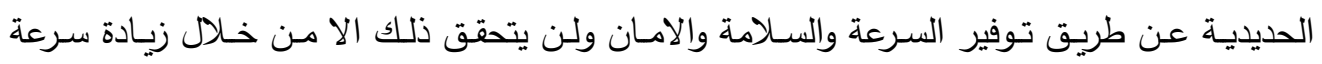
القاطرات وتحديد أسعار مناسبة وبسعر أقل بكثير من النقل بالسيارات. ه. تثجيع القطاع الخاص بفتح مكاتب على غرار مكاتب الخطوط الجوية العراقية وفي أماكن متعددة لتسهيل عملية الحجز، بالإضافة الى استخدام شبكة الانترنت للحجز المسبق.

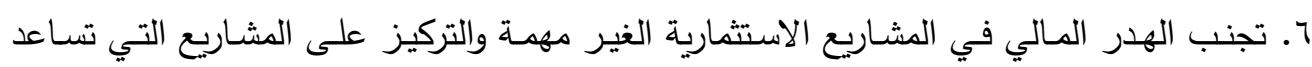

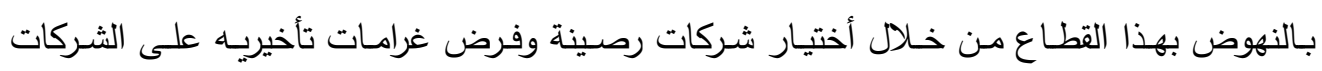

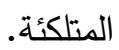

V. تثجيع الاستثمار الاجنبي من خلال شركات عالمية متخصصة في قطاع السكك الحديدية وتوفير كافة التسهيلات للعمل في العراق. 
العدد الثالث والأربعون

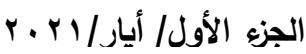

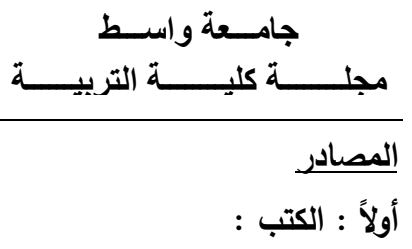

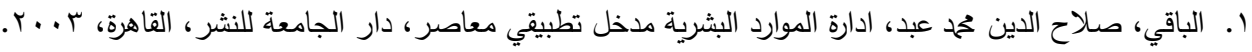

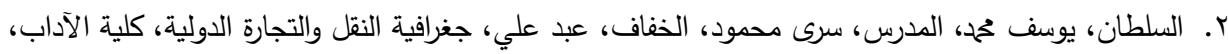

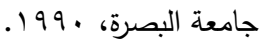

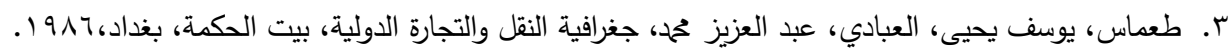

ثانياً : الرسائل والا طاريح : الرئ

ا. البراك، اماني عبد الرزاق، النقل بالسكك الحديدية على طريق ( بغداد - البصرة ) وافاقة المستقبلية، أطروحة دكتوراه،

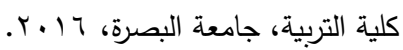
r. محمد رؤوف سعيد، تطور بالسكك الحديد ودوره في اعادة توظيف المنشآت الصناعية الكبيرة في العراق، اطروحة

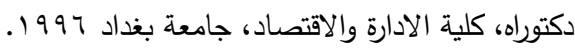

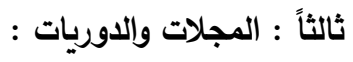

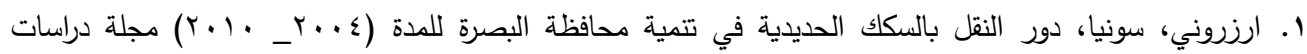

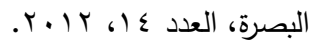
r. الجنابي، خالد محح، السكك الحديد العراقية Yo ع عاماً من العطاء والتألق، صحيفة المثقف، مؤسسة المثقف العربي،

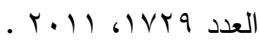

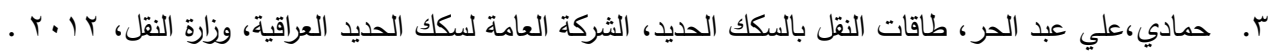

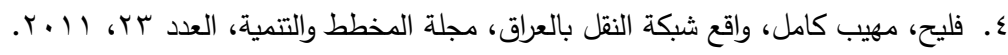

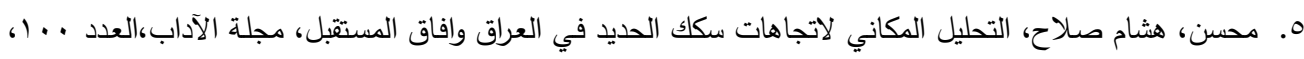
r. I r

\section{رابعاً: التقارير والنشرات السنويـة :} ا. وزارة النقل والمواصلات، الشركة العامة لسكك الحديد العراقية، قسم التخطيط والمتابعة، شعبة الاحصاء، تقارير

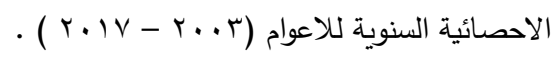

r. وزارة النقل والمواصلات، الثركة العامة لسكك الحديد العراقية، قسم التخطيط والمتابعة، شعبة الاحصاء، تقارير

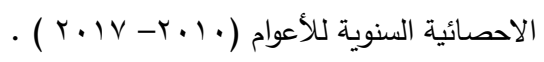

r. وزارة النقل والمواصلات، الثركة العامة لسكك الحديد العراقية، تقرير ديوان الرقابة المالية . ع. وزارة التخطيط، الجهاز المركزي للإحصاء، مديرية احصاءات النقل والاتصالات، ـ. . ب. 
العداد الثالث والأربعون

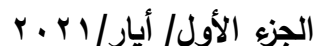

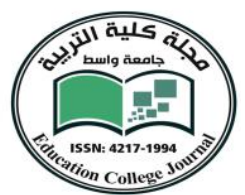

arion College

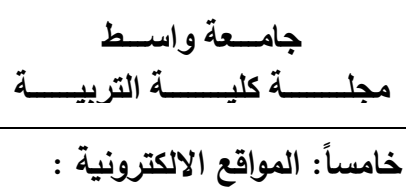

ا . مجلة الثبكة العراقية، الثركة العامة لسكك الحديد - خطط النهوض تواجه معوقات كبيرة

http://magazine.imn.iq/2018،

http://ww.alaraby.com.uk/2019 r. مجلة العربي الجديد، قطارات العراق ومعاناة سائقيها، 